MATEC Web of Conferences 53, 02001 (2016)

DOI: $10.1051 /$ matecconf/20165302001

(C) Owned by the authors, published by EDP Sciences, 2016

\title{
Modern Beer Factory Interwoven in Urban Texture
}

\author{
Violeta Gjorgjevska ${ }^{1, a}$ and Aleksandar Radevski ${ }^{1}$ \\ ${ }^{1}$ Ss Cyril and Methodius University, Faculty of Architecture, Skopje, Macedonia
}

\begin{abstract}
The main idea of this research is to present a concept of integration of a beer factory in a new urban reality. Nowadays, modern development of industrial architecture enables beer factories to leave their typical locations in industrial zones and draw nearer to their customers. To design a modern industrial complex incorporating the ideas of the contemporary way of designing an industrial facility with a clear and indicative architectural expression of its hybrid character requires great skilfulness. Using a linear grid, the concept of this project will be developed in a composition consisting of several strips. This kind of structure creates a compositional equivalence from strip to strip, integrating the natural and the urban, the public and the private.
\end{abstract}

\section{1 introduction}

Striped forms have been part of modern urbanism since the 1920s when a specific type of linear city was formulated by the Soviet planner N.A. Miliutin for the new city of Magnitogorsk. More recently, striped urbanism was revived by OMA [1] in their competition proposal for Parc La Villette in 1982. Although limited as a one-dimensional abstraction, striped urbanism remains a viable alternative to block and street urbanism [2-6].

The aim of this paper is to present the idea how a beer factory can be integrated in strips and thus create a new urban texture [7-12].

\section{Previous experiences - urban strips}

The proposed project for "Parc La Villette " by Rem Koolhaas does not actually refer to any particular park, but rather it presents a method that - combining programmatic instability with architectural specificity - will eventually generate a park. [1]

In La Villette, the strategy of strip operates the whole process to design a social condenser by means of tactical design acts. The strips manage the construction process of the park by means of operational tactics. They are divided and directed in such a manner as to prepare a generic ground on which programmatic elements are distributed, added, and connected. The mutual relationship between strategy and tactics is essential for the design process of La Villette.

The idea is comprised of 5 steps (Figure 1):

${ }^{\text {a }}$ Corresponding author : violeta.gorgevska@yahoo.com

This is an Open Access article distributed under the terms of the Creative Commons Attribution License 4.0, which permits unrestricted use, distribution, and reproduction in any medium, provided the original work is properly cited. 
1. The major programmatic components are distributed in horizontal bands across the site, creating a continuous atmosphere in its length and perpendicular, rapid change in experience.

2. Some facilities - kiosks, playgrounds, barbecue spots are distributed mathematically according to different point grids.

3. The addition of a "round forest" as architectural elements.

4. Connections

5. Superimpositions
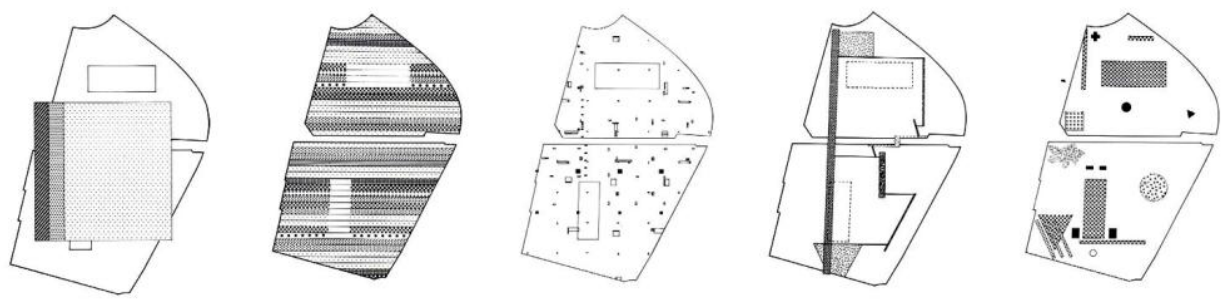

Figure 1. Layers of Parc de la Villette project

\section{Research results - architectural concept}

The initial steps in the development of the concept of urban brewery were the "urban strips". Based on the analysis of all parameters of the urban location and its surroundings, several guiding principles were defined, which articulate the whole area and define the urban settlement [2]:

1. Set the linear grid - forming an urban park in strips

2. Penetration of prisms in the strips - beer factory

3. Differentiation of pedestrian traffic from vehicle traffic, completely separating them by levels.

The primary point in the articulation of the site is its urban settlement as an urban - ecological park. The concept starts with setting a linear grid. It appears that one side of the site significantly dominates over others in length, and hence the linear grid was placed over that side. The grid used a module of $6 \mathrm{~m}$, which is suitable for the constructive solution of the object. Nevertheless, the 6 meter module is one of the main design modules that are used in architectural design. From situational view, the object position occupies two thirds of the parcel and it does not interfere in the space intended for future housing. The other half consists of recreational sports fields, a kids' park, access for visitors, hiking trails ... This part in essence represents a kind of buffer zone between the beer factory and the environment. The whole setting gives an impression that the greenery is interwoven with the building (Figure 2a, b).

a)

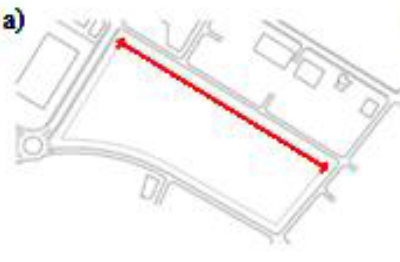

b)

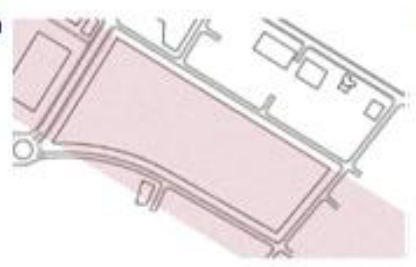

c)

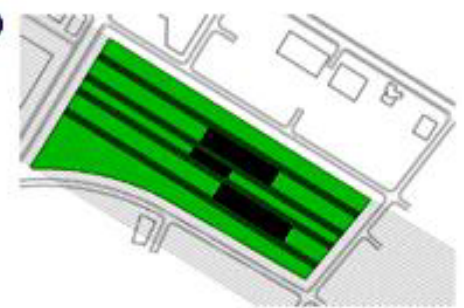

Figure 2.a,b - Linear - forming an urban park in strips; c- Penetration of prisms in strips - beer factory

Based on this scheme 7.4ha were divided into 37 parallel landscape strips, with equal thickness, which cover the entire site. Each strip contains various program activities such as sports and games, and at the same time also different types and positioning of trees, shrubs, fruit orchards, as a kind of open botanical gardens that are not based on scientific classifications, but intended for spontaneous exploration for pure enjoyment. This is a new type of park - ecological park without any stereotypes, 
perfect for socializing of the visitors. In a park like this, every visit is a unique experience. For example, moving through the strips gives you a sequence of landscape experience, while if you cut through the tape, a completely different sequence of perception will be revealed. This type of park can be called a proto- or supra- urban landscape, as its experience evokes qualities that we would like to encounter in all settlements [13-16].

The second step involves penetration of the volumes in the form of individual prisms (Fig.3). They are in a linear disposition. Initially, the whole program was contained in a single long linear volume in accordance with the morphology of the site. This volume was further segmented into three separate volumes, translated into each other to evoke a sense of movement. The tendency of this concept is to interpolate greenery and architecture, to weave one into the other. To create a composition where the prisms will penetrate from the inside, but will not interfere with the environment $[17,18]$.


Figure 3. Differentiation of pedestrian traffic from vehicle traffic

The third step includes the genesis of the traffic solution proposed by the project. Namely, the traffic solution is of utmost importance for the functioning of any industrial complex. The aim of this project is to separate the vehicle from the pedestrian traffic. This will be achieved by leaving linear paths on the ground, connected with the prisms on both sides, while the vehicle traffic will be moved one level below ground level. There is a ramp to access the lower plateau, which connects the three linear prisms that penetrate the surface. This is the way that leads to the storage areas, warehouses and the manufacturing plant [2].

\section{Genesis of ground solution}

The project for urban beer factory is not a project that proposes a definite industrial architecture. The idea behind this project is to apply a method that combines industrial architecture and environment, in order to attain an urban, ecological park (Figure 4).
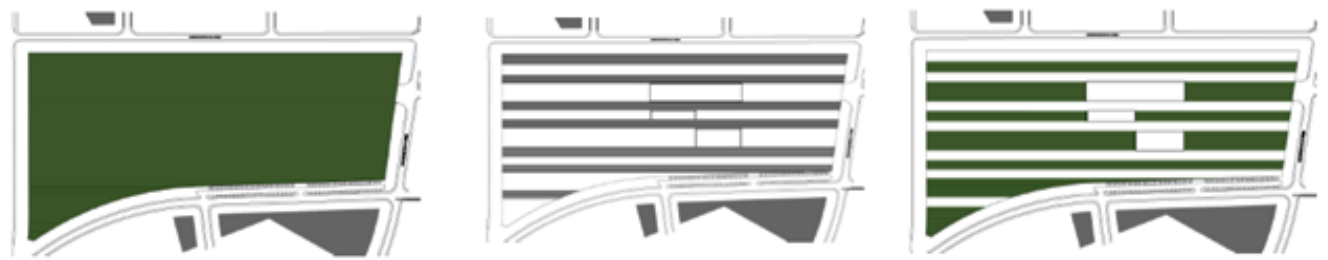

Figure 4. Layers of urban solution

By setting the linear grid, one type of texture is formed from the free, inbuilt surface on the site. A number of bands are reserved for the visitors, to be used as pedestrian bands, while the remaining are intended for greenery. Thus, the concept for an urban beer factory is finalized. By combining of all 
functions a single harmonic composition is formed. A scenario for the concept's operation is provided below [4].
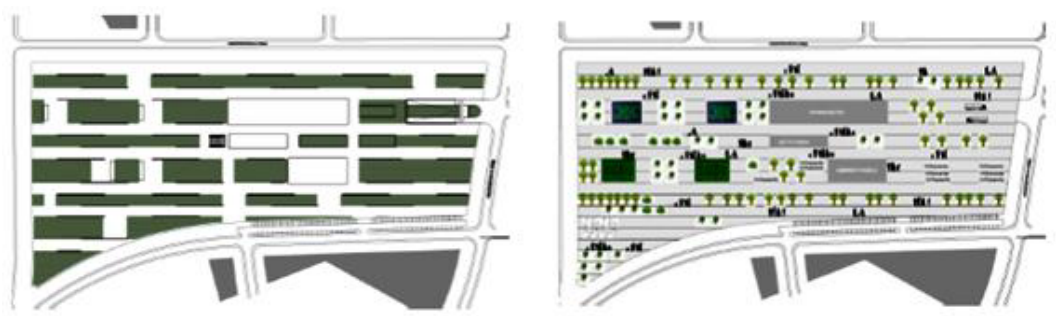

Figure 5. Scenario for functioning of the locations

\section{Designing process - product}

The project for urban beer factory is graphically presented (Fig.6, 7, 8). Everything is designed in strips. That is the aim of the concept. The whole building, which is composed of three prisms that are visible on the ground level, is formed from the same material, concrete and steel panels [2].

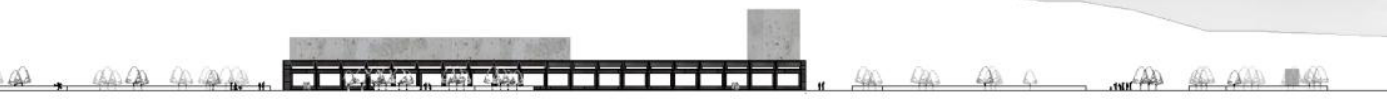

Figure 6. Facade of beer factory

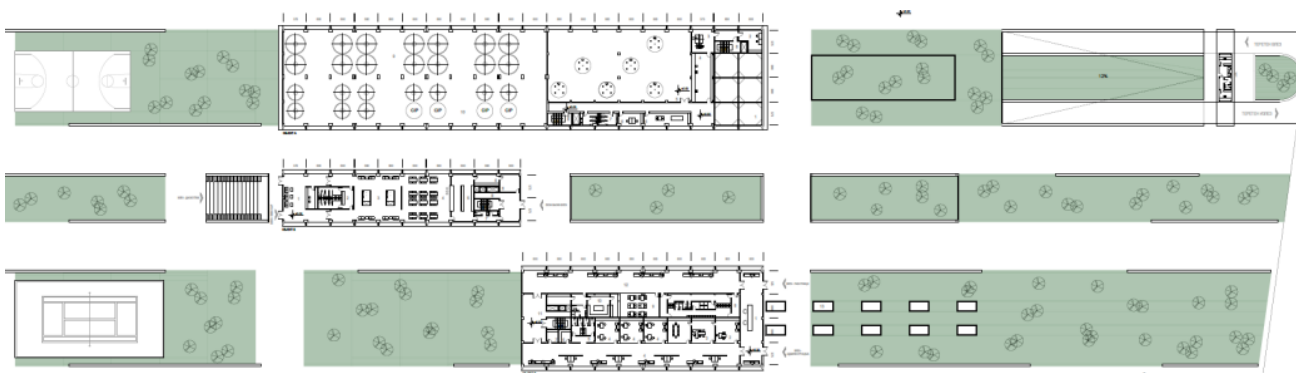

Figure 7. Plan of beer factory

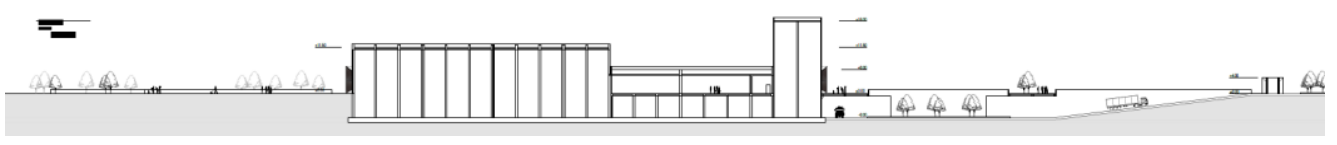

Figure 8. Section of beer factory

\section{Summary}

In the course of its entire development, industrial architecture has undergone countless changes. The contemporary ways of developing industrial facilities enable their relocation from the typical industrial zones into urban areas where they are closer to their customers. Beer factories are examples that demonstrate the changes in the perceptions of the overall picture of the industrial facility, which used to represent a symbol of production, closed within its designed limits. The changing lifestyle, human needs and creativity of architects lifted the brewery to a more advanced level not only in view of the manufacturing plant itself, but also in view of the rest areas, entertainment, recreation, and spaces that can provide for tourism development. 
The aim of this research is to highlight, examine and adjust these production facilities, beer factories, as a part of the new urban reality. To design a modern industrial complex incorporating the ideas of the contemporary way of designing an industrial facility with a clear and indicative architectural expression of its hybrid character requires great skilfulness. Every city needs this type of architecture. The result will be a modern industrial facility, which would be considered as a novelty in architecture in general.

In this sense, this study shows one of the many possible variants for intertwining of such innovative ideas that would lead to a new ideological basis from which would stem modern improved industrial facilities and ultimately, improved architecture in general.

\section{References}

1. Information from: www.oma.eu [7.8.2015].

2. V. Gjorgjevska, Master Thesis, (Architectural Faculty - Skopje, 2014)

3. A. Christopher, The Timeless Way Of Building (Oxford University Press, 1979)

4. Ch. Datz, Ch. Kullman, Winery Design (Neues, Roma, 2006)

5. A. Jüren, K. Hausmann, F. Jüttner, A Design Manual Industrial Buildings (Birkhäuser; Berlin, 2004)

6. H.R. Franzke, Industriebau [Industrial building] (Birkhauser; Berlin, 2001)

7. M. Webb, Adventurous Wine Architecture (Images Publishing, Sidney, 2005

8. R. Krier, Architectural Composition (Rizzoli, New York, 1988)

9. G. Radovic, V. Murgul, N.I. Vatin, Applied Mechanics and Materials, 584-586, 564-569 (2014)

10. V. Murgul, Journal of Applied Engineering Science, 12 (2), 121-128 (2014)

11. J. Ćetković, M. Knežević, M. Žarković, V. Murgul, N. Vatin, Applied Mechanics and Materials, 638-640, 2465-2470 (2014)

12. Y. Nikitin, V. Goryunov, V. Murgul, N. Vatin, Applied Mechanics and Materials, 680, 504-509 (2014)

13. R. Alihodzic, V. Murgul, N. Vatin, Applied Mechanics and Materials, 680, 494-498 (2014)

14. G. Radović, V. Murgul, M. Cvetkovska, E. Aronova, N. Vatin, Journal of Applied Engineering Science, 12 (4), 277 - 284 (2014)

15. G. Radovic, V. Murgul, N. Vatin, Applied Mechanics and Materials, 641-642, 634-638 (2014)

16. M. Penića, S. Golovina, V. Murgul, Procedia Engineering, 117, 883-890 (2015)

17. V. Murgul, N. Vatin, I. Zayats, Procedia Engineering, 117, 824-829 (2015)

18. V. Goryunov, I. Zayats, T. Konjkova, V. Murgul, Procedia Engineering, 117, 825-831 (2015) 